\title{
Protective effect of nicorandil on collapse-induced lung injury in rabbits by inhibiting apoptosis
}

\author{
CHUNGUANG WANG ${ }^{1,2}$, HONGGANG KE ${ }^{3}$, XINGGUO XU ${ }^{2}$, \\ JUNJIE CHEN $^{2}$, DONGYUN SUN ${ }^{4}$ and FUHAI JI ${ }^{1}$ \\ ${ }^{1}$ Department of Anesthesiology, The First Affiliated Hospital of Soochow University, Suzhou, Jiangsu 215006; \\ Departments of ${ }^{2}$ Anesthesiology and ${ }^{3}$ Cardiothoracic Surgery, ${ }^{4}$ Ophthalmic Operating Room, \\ The Affiliated Hospital of Nantong University, Nantong, Jiangsu 226001, P.R. China
}

Received June 10, 2018; Accepted May 24, 2019

DOI: $10.3892 /$ ijmm.2019.4236

\begin{abstract}
The one-lung ventilation (OLV) technique is vital in thoracic surgery. However, it can result in severe lung injury, which is difficult to manage. The main solution at present is the use of ventilation strategies, including continuous positive oxygen pressure, low tidal volume and high frequency ventilation, and the administering of drugs, including phenylephrine, dexmedetomidine and morphine. However, the protective effect of these methods on the lungs is not sufficient to improve the prognosis of patients. Therefore, how to develop a novel protective drug remains an open question. Nicorandil, a mitochondrial (mito)KATP-specific opener, serves an important role in cardioprotection, although its effect on lung injury remains unclear. The present study examined the protective role of nicorandil against collapse-induced lung injury in
\end{abstract}

Correspondence to: Professor Fuhai Ji, Department of Anesthesiology, The First Affiliated Hospital of Soochow University, 188 Shizi Street, Suzhou, Jiangsu 215006, P.R. China

E-mail: jifuhai@suda.edu.cn

Abbreviations: OLV, one-lung ventilation; TLV, two-lung ventilation; I/R, ischemia/reperfusion; mitoKATP, mitochondrial ATP-sensitive potassium channels; HPV, hypoxemic pulmonary vasoconstriction; $\mathrm{H} \& \mathrm{E}$, hematoxylin and eosin; $\mathrm{SaO}_{2}$, arterial oxygen saturation; $\mathrm{S}_{\mathrm{P}} \mathrm{O}_{2}$, pulse oxygen saturation; $\mathrm{PaO}_{2}$, arterial partial pressure for oxygen; MDA, malondialdehyde; TNF- $\alpha$, tumor necrosis factor- $\alpha$; SOD, superoxide dismutase; ELISA, enzyme-linked immunosorbent assay; TUNEL, terminal deoxynucleotidyl transferase transfer-mediated dUTP nick end-labeling; PI3K, phosphatidylinositol-3-kinase; Akt, protein kinase B; NF- $\kappa \mathrm{B}$, nuclear factor- $\kappa \mathrm{B}$; HIF-1 $\alpha$, hypoxia-inducible factor $1 \alpha$; RT-qPCR, reverse transcription-quantitative polymerase chain reaction; caspase-3, cysteinyl aspartate-specific proteinase-3; W/D ratio, wet/dry weight ratio; V/Q, ventilation/perfusion; $\mathrm{mPTP}$, mitochondrial membrane permeability transition pore; VILI, ventilator-induced lung injury; VIDD, ventilator-induced diaphragm dysfunction

Key words: nicorandil, collapse-induced lung injury, OLV, apoptosis, PI3K/Akt, NF- $\kappa$ B, HIF-1 $\alpha$, Bax/Bcl2, caspase-3 rabbits undergoing OLV. Changes in arterial oxygen saturation $\left(\mathrm{SaO}_{2}\right)$, arterial partial pressure for oxygen $\left(\mathrm{PaO}_{2}\right)$, wet/dry weight ratio, and the microstructure of tissues and cells were observed. Enzyme-linked immunosorbent assays were used to determine the concentrations of malondialdehyde (MDA) and tumor necrosis factor (TNF)- $\alpha$, and the activity of superoxide dismutase (SOD) in rabbits treated with nicorandil. Terminal deoxynucleotidyl transferase transfer-mediated dUTP nick end-labeling was used to detect apoptosis and western blotting was used to analyze the relative proteins involved in apoptosis. Western blotting and reverse transcription-quantitative polymerase chain reaction analysis were used to examine the expression of hypoxia inducible factor $1 \alpha(\mathrm{HIF}-1 \alpha)$, phosphatidylinositol-3-kinase (PI3K), protein kinase B (Akt) and nuclear factor (NF) $-\kappa \mathrm{B}$ in the lungs of rabbits treated with nicorandil. The $\mathrm{SaO}_{2}$ and $\mathrm{PaO}_{2}$ in the high-dose group were significantly higher than those in the control group in the process of OLV. The wet/dry weight ratio, and the concentrations of MDA and TNF- $\alpha$ in the collapsed lung of the high-dose group were significantly lower than those in the control group. The activity of SOD in the high-dose group was significantly higher than that in the control group. The lung had improved microstructure and less apoptosis, which was determined by the $\mathrm{Bax} / \mathrm{Bcl} 2$ ratio in the high-dose group. The expression levels of PI3K, phosphorylated Akt and HIF-1 $\alpha$ were upregulated, whereas the expression of $\mathrm{NF}-\kappa \mathrm{B}$ was downregulated. In conclusion, nicorandil had a protective effect via inhibiting apoptosis in non-ventilated lung collapsed and re-expansion during OLV in the rabbit. It acted on mitoKATP through the PI3K/Akt signaling pathway.

\section{Introduction}

Evidence $(1,2)$ shows that mitochondria are the main target following ischemia/reperfusion (I/R), and the mitochondrial ATP-sensitive potassium channels (mitoKATP) are located in the mitochondrial inner membrane of important organs, including the heart, brain and lungs, serving an important role in the lung following I/R injury. The mitochondria, which generate reactive oxygen species as a key medium (3), are the triggering factor and end effector of I/R injury. I/R lung injury is a typical manifestation of one-lung ventilation (OLV). 
OLV has been widely used in thoracic surgery anesthesia (4). It can prevent secretions and blood from the lung undergoing surgery from flowing into the contralateral lung, ensuring the patency of airways and collapse of the lung undergoing surgery without cross-infection and proliferation of lesions. With the extensive application of thoracoscopic surgical techniques, OLV technique, which facilitates the visual development of thoracic surgery and makes surgery easier to perform, has become essential. However, the inhibition of hypoxemic pulmonary vasoconstriction (HPV), hypoxemia, generation of oxygen free radicals, ischemia/reperfusion (I/R) injury (5) and inflammatory reactions (6) may occur during OLV, and are mainly found in the lung being operated on, leading to lung injury, which is difficult to manage. Current solutions are continuous positive airway pressure and low-flow oxygen insufflation $(7,8)$, which can reduce the accumulation of inflammatory cytokines and moisture, improve oxygenation and reduce lung injury. There is a reasonable selection of anesthetic or vasoactive drugs to protect the lungs, including dexmedetomidine, isoflurane $(9,10)$, morphine and phenylephrine (11). Protective ventilation strategies, including low tidal volume and high frequency ventilation, represent other ways to reduce lung injury $(7,8)$.

To date, the protective effect of these methods on the lungs is far from ideal. Therefore, the investigation of novel types of protective drug has become important. According to the basic principles of cell and tissue protection, concern lies on the focal point of oxidative stress, the mitochondria, and it is reasonable to focus on its KATP agonists.

Nicorandil, a Food and Drug Administration-approved mitoKATP-specific opener, activates the opening of the mitoKATP to protect cells. In the context of cardiology, several reports $(12,13)$ have highlighted the key function in protecting the heart (14). However, only one study (15) has focused on the reduction of lung injury caused by cyclophosphamide. In the present study, a mature rabbit OLV model was used to investigate the protective effect of nicorandil on lung injury and to examine its mechanisms.

\section{Materials and methods}

Animals and groups. A total of 36 healthy three month-old male Japanese big-ear white rabbits weighing $2.6-3.2 \mathrm{~kg}$ were provided by the Laboratory Animal Center of Nantong University (Nantong, China). The animals were raised under controlled environmental conditions of a constant temperature $\left(25 \pm 2^{\circ} \mathrm{C}\right)$ and a $12 / 12 \mathrm{~h} \mathrm{light} / \mathrm{dark}$ cycle. Food for the rabbits was provided by Pizhou Dongfang Breeding Co., Ltd. (Xuzhou, China), which was available ad libitum with water. The physiological status of male animals without fixed physiological cycle is more stable than that of female animals, and the difference between individuals is smaller. (16) The hormone levels in the body are stable and enzyme activity is relatively stable. The investigation was approved by the Ethics Committee for Animal Experimentation of Nantong University. The rabbits were randomly divided into six groups $(n=6)$. Group 1 served as the sham group. Group 2 served as the control group. Groups 3 and 4 served as the high-dose and low-dose nicorandil groups, respectively. Group 5 served as the high-dose nicorandil + glibenclamide group (injected for $1 \mathrm{~h}$ at $22^{\circ} \mathrm{C}$; 99\%; cat. no. G0639; Sigma-Aldrich; Merck KGaA, Darmstadt, Germany). LY294002 (injected for $1 \mathrm{~h}$ at $22^{\circ} \mathrm{C} ; 98 \%$; cat. no. L9908; Sigma-Aldrich; Merck KGaA) was applied with a high dose of nicorandil for examining its signaling pathway in group 6 rabbits (Fig. 1).

Rabbit OLV model establishment. A rabbit OLV model was established, as previously described $(17,18)$. Nicorandil is a mature drug used in cardiovascular medicine, with an advised usual dose of $2 \mathrm{mg} / \mathrm{h}$ in the specifications (19). The conventional dose for rabbits was then calculated as a high dose $(100 \mu \mathrm{g} / \mathrm{kg} \cdot \mathrm{h})$, half of which was defined as a low dose, according to the rabbit body and human body surface area conversion formula. The rabbits were induced with $2 \%$ odium pentobarbital $(20 \mathrm{mg} / \mathrm{kg}),(20)$ and then maintained under $10 \%$ propofol ( $5 \mathrm{mg} / \mathrm{kg} \cdot \mathrm{h}), 2 \%$ sodium pentobarbital $(4 \mathrm{mg} / \mathrm{kg})$ each for $30 \mathrm{~min}$, and vecuronium bromide $(0.25 \mathrm{mg} / \mathrm{kg} \cdot \mathrm{h})(21,22)$. Following induction, the right common carotid artery was cannulated to monitor arterial blood pressure and arterial blood samples were collected. Tracheotomy and a self-made double-lumen endotracheal tube were used for mechanical ventilation. The parameters were as follows: $\mathrm{FiO}_{2}, 1.0$; RR, $40 \mathrm{bpm} ; \mathrm{VT}, 10 \mathrm{ml} / \mathrm{kg}$. Auscultation was used to adjust the position of the endotracheal tube. The animal was adjusted into a right lateral position, and the left lumen was closed to establish the rabbit OLV model; thoracotomy was performed to directly observe whether the left lung had collapsed. At $1 \mathrm{~h}$ post-OLV, both lungs were ventilated for $30 \mathrm{~min}$. The rabbits were under anesthesia with propofol and sodium pentobarbital. At the end of each experiment, the animals were sacrificed by injection of a lethal dose of pentobarbital sodium (23). In the absence of mechanical ventilation, $100 \mathrm{mg} / \mathrm{kg}$ sodium pentobarbital was injected through the ear vein. No respiratory motion, no heartbeat and no detectable $\mathrm{S}_{\mathrm{p}} \mathrm{O}_{2}$ were observed in the rabbit, which confirmed the rabbit had died. The operated lung was rapidly excised and washed with ice-cold saline. One part was dried and weighed, the other was preserved at $-80^{\circ} \mathrm{C}$. Changes in $\mathrm{SaO}_{2}$ and $\mathrm{PaO}_{2}$ were observed in the perioperative period. Following surgery, the wet/dry ratio was measured. Changes of the microstructure of the lung tissues were observed by hematoxylin and eosin (H\&E) staining and transmission electron microscopy. The concentrations of malondialdehyde (MDA; cat. no. S0131; Beyotime Institute of Biotechnology, Haimen, China) and tumor necrosis factor- $\alpha$ (TNF- $\alpha$; cat. no. PT512; Beyotime Institute of Biotechnology) and the activity of superoxide dismutase (SOD; cat. no. S0101; Beyotime Institute of Biotechnology) were measured by ELISA. Terminal deoxynucleotidyl transferase transfer-mediated dUTP nick end-labeling (TUNEL) was used to observe the apoptosis of lung tissues. The expression of phosphatidylinositol-3-kinase (PI3K), protein kinase B (Akt), phosphorylated (p-)Akt, nuclear factor- $\kappa \mathrm{B}(\mathrm{NF}-\kappa \mathrm{B})$ and hypoxia-inducible factor $1 \alpha(\mathrm{HIF}-1 \alpha)$ were detected by western blotting. Reverse transcription-quantitative polymerase chain reaction (RT-qPCR) analysis was used to detect the transcription of HIF-1 $\alpha$ mRNA in lung tissues. The expression of downstream proteins $\mathrm{Bax}, \mathrm{Bcl} 2$ and caspase- 3 were detected by western blotting.

Wet/dry (W/D) weight ratio. Following collection, the operated lung was weighed for its wet weight, and then placed in an oven 


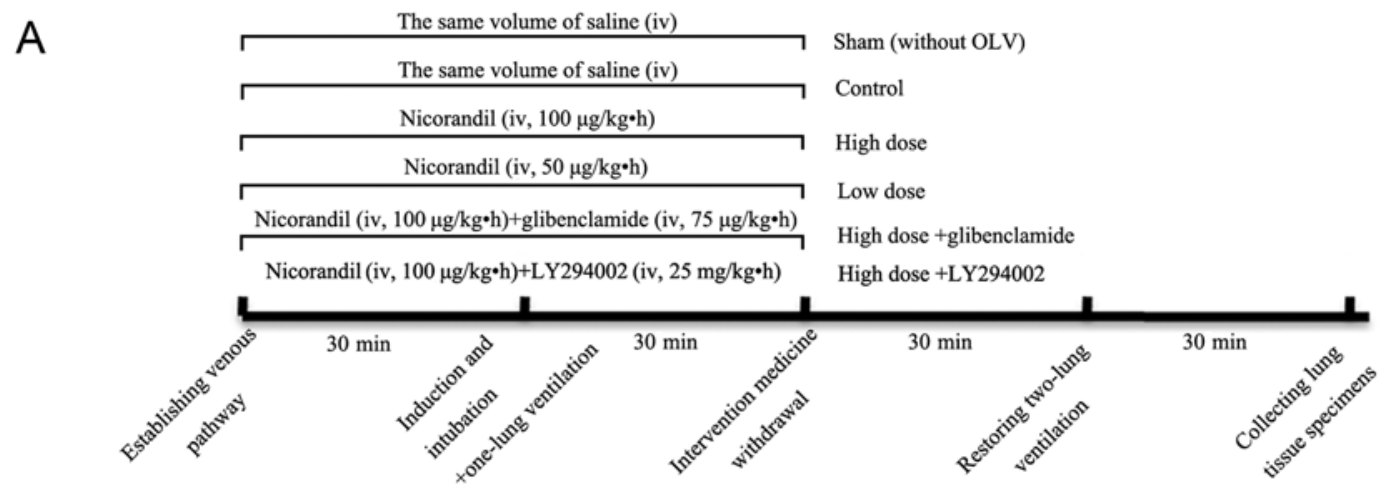

B

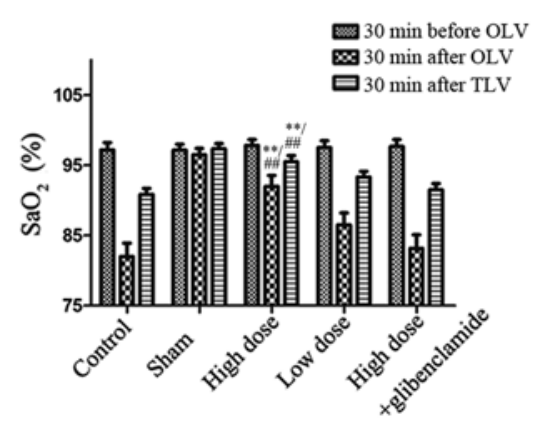

C

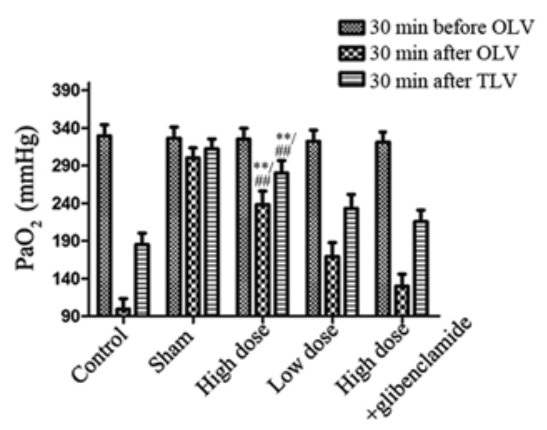

D

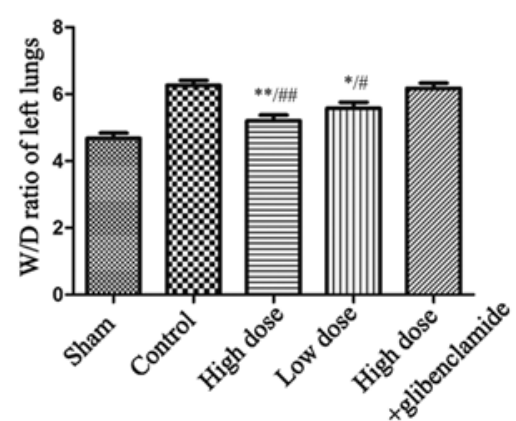

Figure 1. Experimental grouping, schematic of the establishment protocol and the effect of nicorandil on lung oxygenation and water accumulation in a rabbit with collapse-induced lung injury. (A) Experimental grouping and schematic of the model establishment process. (B) Effect of nicorandil on SaO ${ }_{2}$ via arterial blood gas analysis. (C) Effect of nicorandil on $\mathrm{PaO}_{2}$ via arterial blood gas analysis. (D) Effect of nicorandil on the W/D weight ratio of lung was measured using an electronic balance. ${ }^{*} \mathrm{P}<0.05$ and ${ }^{* *} \mathrm{P}<0.01$ vs. control group; ${ }^{\#} \mathrm{P}<0.05$ and ${ }^{\# \#} \mathrm{P}<0.01$ vs. glibenclamide group. OLV, one-lung ventilation; SaO ${ }_{2}$, arterial oxygen saturation; $\mathrm{PaO}_{2}$, arterial partial pressure for oxygen; W/D ratio, wet/dry weight ratio.

$\left(80^{\circ} \mathrm{C}, 48 \mathrm{~h}\right)$, and heated to a constant weight. In the following day, the dry weight was determined and the W/D weight ratio of the lung was calculated.

Measurement of the lung injury score (H\&E staining). For histopathological analysis, the lung tissues were fixed in $4 \%$ formalin at $4^{\circ} \mathrm{C}$ for $24 \mathrm{~h}$ and embedded in paraffin. Subsequently, sections (5- $\mu \mathrm{m}$ thick) were prepared, stained with $\mathrm{H} \& \mathrm{E}$ at $22^{\circ} \mathrm{C}$ for $30 \mathrm{sec}$ for pathological observation, and then examined using a light microscope (magnification, $x 40$ ). The lung injury score of each slide was assessed by two independent pathologists in a blinded manner. The score represents the average of the pathologists scores. Each section was scored according to the following four criteria (24): i) Alveolar septal congestion; ii) alveolar hemorrhage; iii) intra-alveolar cell infiltrates; and iv) intra-alveolar fibrin deposition.

Transmission electron microscopy. Lung tissue sections $\left(1-\mathrm{mm}^{3}\right)$ were fixed in $2.5 \%$ glutaraldehyde at $4^{\circ} \mathrm{C}$ for $24 \mathrm{~h}$, followed by $1 \%$ osmium tetroxide and embedded in epoxy resin 618. Subsequently, these samples were cut into ultrathin sections $(0.5 \mu \mathrm{m})$ and then examined using a Hitachi HT-7700 transmission electron microscope (magnification, x3,000; HT-7700; Hitachi, Tokyo, Japan).

TUNEL assay. When a cell undergoes apoptosis, it activates a number of endonucleases that can cut off nucleosomal DNA. When genomic DNA is disrupted, the exposed 3'-OH can be labeled with fluorescein-dUTP by terminal deoxynucleotidyl transferase (TdT) so that it can be detected by fluorescence microscopy. In this way, TUNEL (cat. no. A112; Vazyme, Piscataway, NJ, USA) was used for the detection of apoptosis. The specific procedures for the paraffin sections were as follows: Dewaxing, in which moisture was increased with ethyl alcohol; protein dissolved with proteinase $\mathrm{K}$; immersing DNA in equilibration buffer (DNA incubated with TDT buffer containing FITC-12-DUTP labeling mix) for $1 \mathrm{~h}$ at $37^{\circ} \mathrm{C}$; nuclear staining with Hoechst $(20 \mathrm{mg} / \mathrm{ml})$ for $10 \mathrm{~min}$ at $22^{\circ} \mathrm{C}$; and observation of slides after mounting in neutral gum with a fluorescent microscope in at least three different fields.

Western blot analysis. The lung tissues were homogenized with lysis buffer (cat. no. KPG250; Nanjing KeyGen Biotech Co., Ltd., Nanjing, China), which contained protease inhibitor, phosphatase inhibitor and phosphorylase inhibitor. The homogenate was incubated at $4^{\circ} \mathrm{C}$ for $30 \mathrm{~min}$ and then centrifuged at $14,300 \mathrm{x} \mathrm{g}$ for $15 \mathrm{~min}$ at $4^{\circ} \mathrm{C}$. The supernatant was harvested and stored at $-80^{\circ} \mathrm{C}$ for further analysis. Total protein concentration in the supernatant was measured using a BCA protein assay. Subsequently, $300 \mu \mathrm{g}$ protein in each group was separated on $5 / 10 \%$ SDS-PAGE gels by electrophoresis and then transferred onto a polyvinylidene difluoride membrane (EMD Millipore, Billerica, MA, USA). Following blocking with 5\% fat-free milk for $2 \mathrm{~h}$ at $22^{\circ} \mathrm{C}$, the membranes were incubated with primary antibodies against NF- $\kappa \mathrm{B}(1: 500$, cat. no. MAB3026; EMD Millipore) or $\beta$-actin $(1: 1,000$; cat. no. 3700 , Santa Cruz Biotechnology, Inc., Dallas, TX, USA) overnight at $4^{\circ} \mathrm{C}$. Following washing three times with TBST, the membranes were 


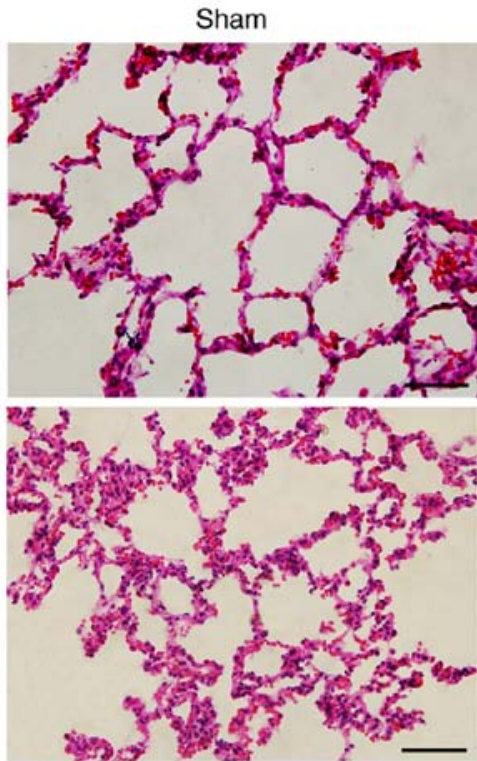

High dose

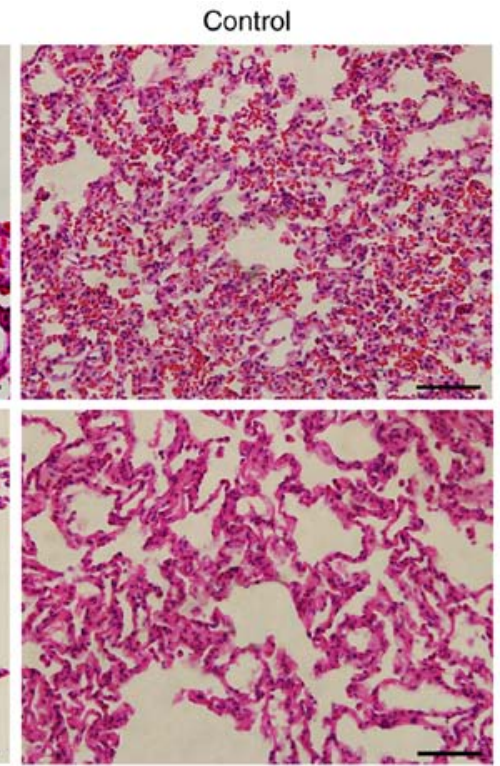

Low dose

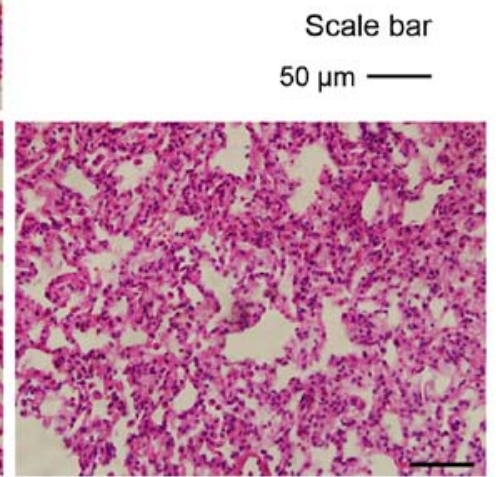

High dose+glibenclamide

Figure 2. Protective effect of nicorandil on collapse-induced lung injury by one-lung ventilation. Effects were detected by hematoxylin and eosin staining. Scale bar, $50 \mu \mathrm{m}$.

incubated with horseradish peroxidase-conjugated secondary antibody (1:5,000; cat. no. AP124P; EMD Millipore) for $2 \mathrm{~h}$ at room temperature. The protein bands were visualized using an ECL system (cat. no. K-12045; Advansta, San Jose, CA, USA). The PI3K (1:1,000; cat. no. AF1966; Beyotime Institute of Biotechnology), Akt (1:1,000; cat. no. AF0045; Beyotime Institute of Biotechnology), p-Akt (1:1,000; cat. no. AF1546; Beyotime Institute of Biotechnology), HIF-1 $\alpha$ (1:500; cat. no. NB100-105; Novus International, Inc., St Charles, MO, USA), Bax (1:1,000; cat. no. AB026; Beyotime Institute of Biotechnology), Bcl2 (1:1,000; cat. no. AF0060; Beyotime Institute of Biotechnology) and caspase-3 (1:1,000; cat. no. 9665; Santa Cruz Biotechnology, Inc.) proteins were assayed using the same method, however, bovine serum albumin $(5 \mathrm{mg} / \mathrm{ml}$; cat. no. P007; Beyotime Institute of Biotechnology) was used for blocking and as a medium to incubate the primary antibody for the detection of p-Akt.

$R T-q P C R$ analysis. Total RNA from the lung tissue specimens was extracted with TRIzol ${ }^{\circledR}$ reagent (Sigma-Aldrich; Merck KGaA). The cDNA was amplified by PTC-200 according to the RT-PCR kit instructions. PCR was performed on the basis of cDNA. The primer sequences were as follows: HIF-1 $\alpha$ (NM_001082782), upstream 5'-CAACATCACCAC CATACA-3' and downstream 5'-TCAGGAGCAGTAGTT CTTT- 3 '. The length of the amplified product was $148 \mathrm{bp}$. The amplification reaction conditions were as follows: $94^{\circ} \mathrm{C}$ pre-denaturation for $3 \mathrm{~min}, 94^{\circ} \mathrm{C}$ denaturation for $30 \mathrm{sec}, 56^{\circ} \mathrm{C}$ annealing for $30 \mathrm{sec}, 72^{\circ} \mathrm{C}$ extension for $45 \mathrm{sec}, 32$ cycles. The primer sequences for GAPDH (NM_001082253) were as follows: Upstream 5'-AGAGCACCAGAGGAGGACG-3' and downstream 5'-CTGGGATGGAAACTGTGAAGAG-3', with a product $105 \mathrm{bp}$. The amplification reaction conditions were as follows: $94^{\circ} \mathrm{C}$ pre-denaturation for $3 \mathrm{~min}, 94^{\circ} \mathrm{C}$ denaturation for $30 \mathrm{sec}, 57^{\circ} \mathrm{C}$ annealing for $30 \mathrm{sec}, 72^{\circ} \mathrm{C}$ extension for $45 \mathrm{sec}$, 32 cycles. SYBR Green PCR Master mix was used to generate fluorescence. The fluorescence intensity was measured using a real-time fluorescence qPCR instrument for the results using the $2^{-\Delta \Delta \mathrm{Cq}}$ method (25), which were on the basis of the sham group.

Statistical analysis. All data are presented as the mean \pm standard error of the mean and each experiment was repeated at least three times. The results were analyzed by one-way analysis of variance with Bonferroni's correction for the post-hoc comparisons. Statistical analysis was performed using GraphPad Prism software (version 5; GraphPad Software, Inc., La Jolla, CA, USA). For all of the statistical tests, $\mathrm{P}<0.05$ was considered to indicate a statistically significant difference.

\section{Results}

Effect of nicorandil on lung oxygenation and water accumulation in rabbits with collapse-induced lung injury. By measuring $\mathrm{SaO}_{2}$ and $\mathrm{PaO}_{2}$, the respiratory status was evaluated. It was observed that the pressure in the airway was significantly upregulated in OLV. The $\mathrm{SaO}_{2}$ and $\mathrm{PaO}_{2}$ in the high-dose group were significantly higher than those in the control group in the process of OLV $(\mathrm{P}=0.0012$ and $\mathrm{P}=0.0001$, respectively). In accordance with the previous findings, the W/D weight ratio of the collapsed lung in the high-dose group was significantly lower than that in the control group $(\mathrm{P}=0.0008)$ (Fig. 1). These data validate the hypothesis that nicorandil can improve lung oxygenation and decrease edema of the lung.

Effect of nicorandil on collapse-induced lung injury by improving its microstructure. Based on the H\&E staining images, there was severe damage to the alveolar microstructure, in which some alveoli had collapsed and disappeared in the control group. Consequently, marked hemorrhage and 


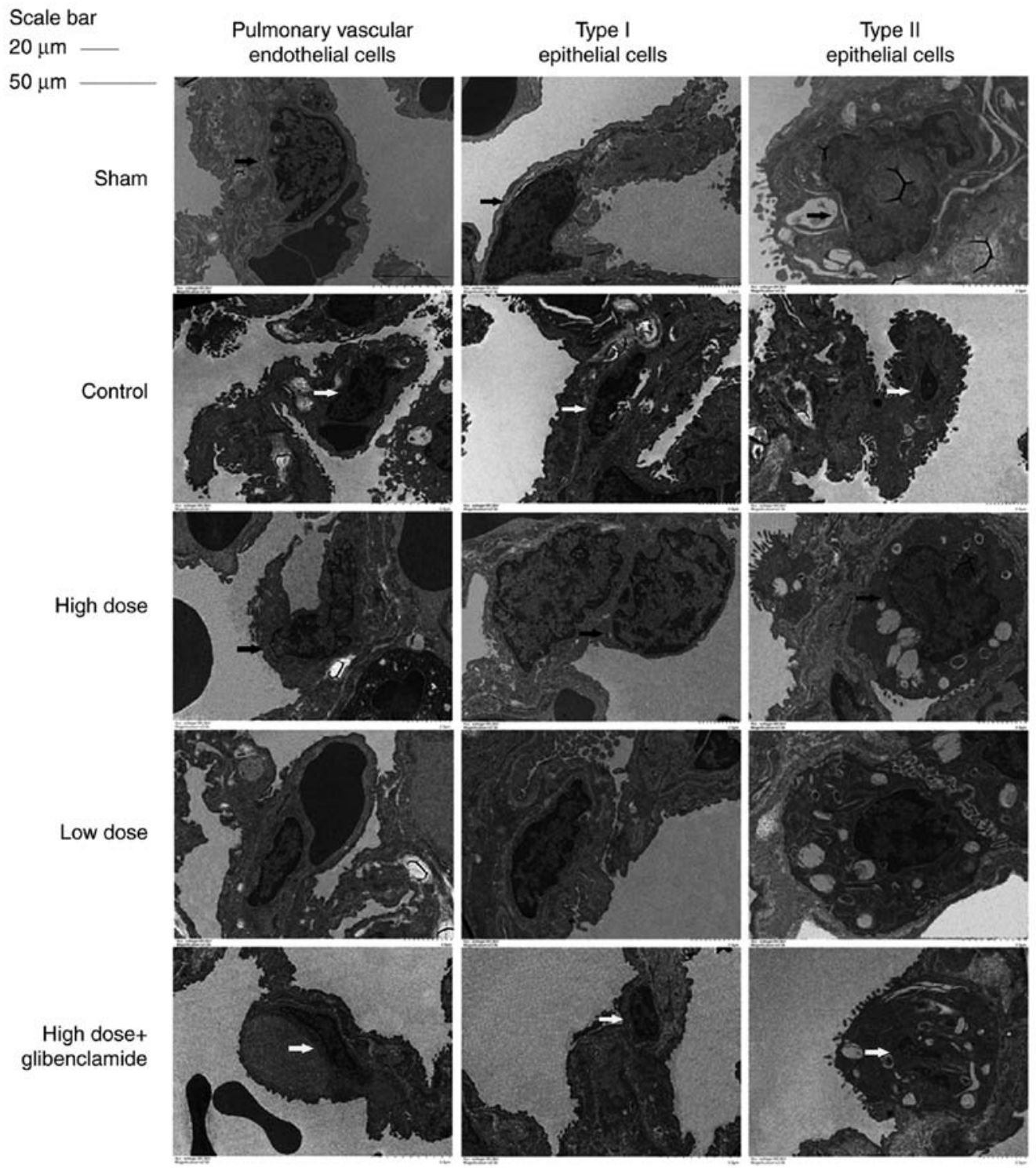

Figure 3. Protective effect of nicorandil on collapse-induced lung injury by one-lung ventilation. Effects were detected by electron microscopy. White arrows indicate abnormal nucleus, black arrows indicate normal nucleus. Scale bar, 20 or $50 \mu \mathrm{m}$.

hyperemia were observed in the lung tissue. There was more infiltration of erythrocytes and inflammatory cells in the alveolar cavity. The alveolar wall was hyperemic, thickened and with serous exudation, and a transparent membrane had formed (Fig. 2).

According to results of electron microscopy, the three types of nuclei exhibited shrinkage, a lobed state and broadening of the perinuclear space. The type II epithelial cell lamellar body was significantly evacuated and the microvilli on the cell membrane became smaller and less numerous (Fig. 3). These results validate the hypothesis that nicorandil can protect the collapsed lung via improving its microstructure.

Mechanism underlying the effect of nicorandil on collapse-induced lung injury by decreasing oxidative stress. The oxidative stress status, which is a mechanism of protection, was evaluated by the measurement of MDA, TNF- $\alpha$ and the activity of SOD. The levels of MDA and TNF- $\alpha$ in the collapsed lung of the high-dose group were significantly lower than those in the control group $(\mathrm{P}=0.0008$ and $\mathrm{P}<0.0001$, respectively). The activity of SOD in the high-dose group was significantly higher than that in the control group $(\mathrm{P}<0.0001$; Fig. 4). These results confirm the hypothesis that nicorandil can protect the collapsed lung by decreasing oxidative stress.

Mechanism underlying the effect of nicorandil on collapse-induced lung injury by inhibiting apoptosis. The results of alveolar apoptosis were observed following a TUNEL assay under a fluorescent microscope. In the control group and glibenclamide group, there were significant increases in the number of apoptotic cells, which was consistent with the positive control group in the TUNEL assay (Fig. 5). Taken together, the results of the high-dose group showed a significant decrease in apoptosis, compared with that in the control group, similar to that in the sham group, and was partially reversed by glibenclamide. A high dose of nicorandil demonstrated better results compared with a low dose of nicorandil. The expression levels of Bax and caspase- 3 in the high-dose group were significantly lower than those in the control group $(\mathrm{P}=0.0085$ and $\mathrm{P}=0.0056$, respectively). By contrast, the expression of 

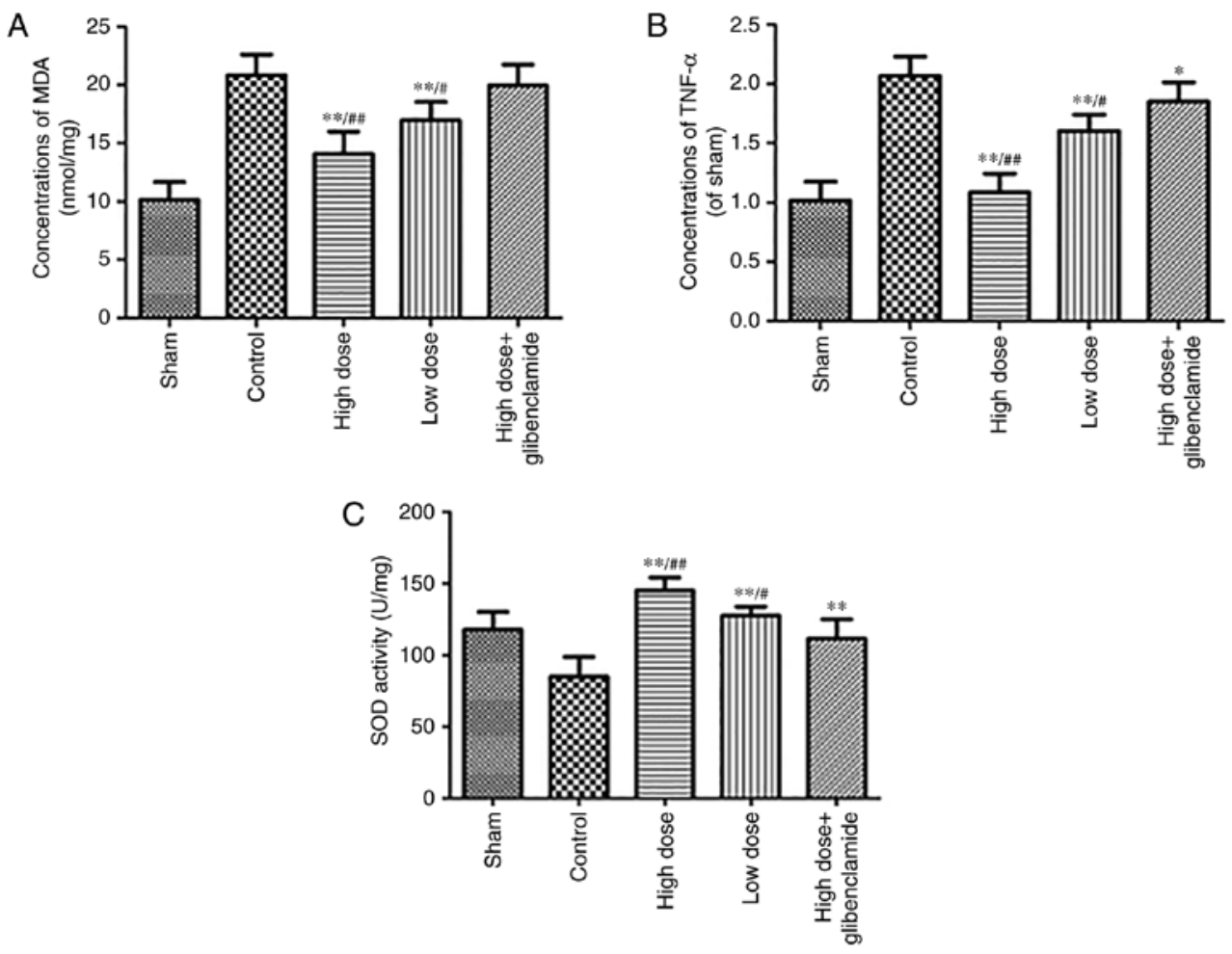

Figure 4. Effects of nicorandil on the activity of SOD and concentrations of MDA and TNF- $\alpha$, measured by enzyme-linked immunosorbent assay. Nicorandil downregulated the concentrations of (A) MDA and (B) TNF- $\alpha$ proteins in the collapsed lung, but (C) upregulated the activity of SOD. "P<0.05 and ${ }^{* *} \mathrm{P}<0.01$ vs. control group; ${ }^{\#} \mathrm{P}<0.05$ and ${ }^{\# \#} \mathrm{P}<0.01$ vs. glibenclamide group. MDA, malondialdehyde; TNF- $\alpha$, tumor necrosis factor- $\alpha$; SOD, superoxide dismutase.

$\mathrm{Bcl} 2$ in the high-dose group was significantly higher than that in the control group $(\mathrm{P}=0.036)$ (Fig. 6A-D). These results were also reversed by glibenclamide, with a low dose of nicorandil having less effect.

Signaling pathway involved in the mechanism of nicorandil on collapse-induced lung injury. The PI3K/Akt signaling pathway is a classical signal transduction pathway. NF- $\kappa \mathrm{B}$ and HIF-1 $\alpha$ form the bond between Akt and downstream genes. It was observed that the expression levels of p-Akt and PI3K in the high-dose group were significantly higher than those in the control group $(\mathrm{P}<0.0001$ and $\mathrm{P}=0.0039$, respectively). The results were reversed by LY294002 $(\mathrm{P}=0.0004$ and $\mathrm{P}=0.0001$, respectively). The protein expression of $\mathrm{NF}-\kappa \mathrm{B}$ in the high-dose group was significantly lower than that in the control group $(\mathrm{P}=0.0005)$. The protein and mRNA levels of HIF-1 $\alpha$ in the high-dose group were significantly higher than those in the control group $(\mathrm{P}<0.0001$ and $\mathrm{P}<0.0001$; respectively; Figs. 7A-F and 8).

\section{Discussion}

Nicorandil has been widely used for cardioprotection in angina pectoris and myocardial infarction (26-28). It has almost no effect on blood pressure or heart rate when it is applied in clinical practice $(29,30)$. It also has been used in protection of the brain (31), liver (32), lungs (12) and kidneys (33). However, there is currently no evidence regarding its application in OLV. With the extensive application of thoracoscopic techniques in surgery, OLV has become essential. However, the inhibition of HPV, imbalance of ventilation/perfusion (V/Q), damage from reactive oxygen free radicals, I/ $\mathrm{R}$ injury and inflammatory reactions, and even mechanical and pressure injury, can result in lung injury, which has a serious impact on patients. Compared with two-lung ventilation (TLV), an increase in peak airway pressure of $\sim 55 \%$ occurs during OLV $(34,35)$. Szegedi et al (36) firstly demonstrated that the effect of gravity on V/Q matching, independent of HPV, resulted in more severe oxidative stress on the operated lung. Misthos et al (37) reported that reactivation of the collapsed lung can activate severe oxidative stress, which was correlated with the time of OLV by reviewing 212 cases between 2001 and 2003 of lung injury caused by re-expansion and reperfusion. Lung I/R injury, which is difficult to manage, always occurs during OLV. Although ventilation strategies and drugs have been found to treat this, the results remain unsatisfactory in terms of improving the prognosis of patients. The present study may provide a novel program to protect lung tissues during OLV. The pathophysiological mechanism in OLV may be multifactorial, and its further examination requires a suitable animal model to be established. In the present study, a well-established rabbit OLV model was used, which has been confirmed to be mature and similar to clinical procedures. The suitable diameter of the endotracheal tube is particularly important; the maximum diameter of the left branch of the double-lumen endotracheal tube was $3.0 \mathrm{~mm}$, which is consistent with the internal diameter of the left bronchus of the rabbit. The appropriate pipe length was $20 \mathrm{~cm}$. Its specific shape was key to ensure the success rate of endotracheal intubation. However, the double-lumen tube is a 'double-edged sword', which in turn leads to lung damage. OLV, which is one of the most challenging techniques for anesthesiologists, is an intraoperative vital ventilation 


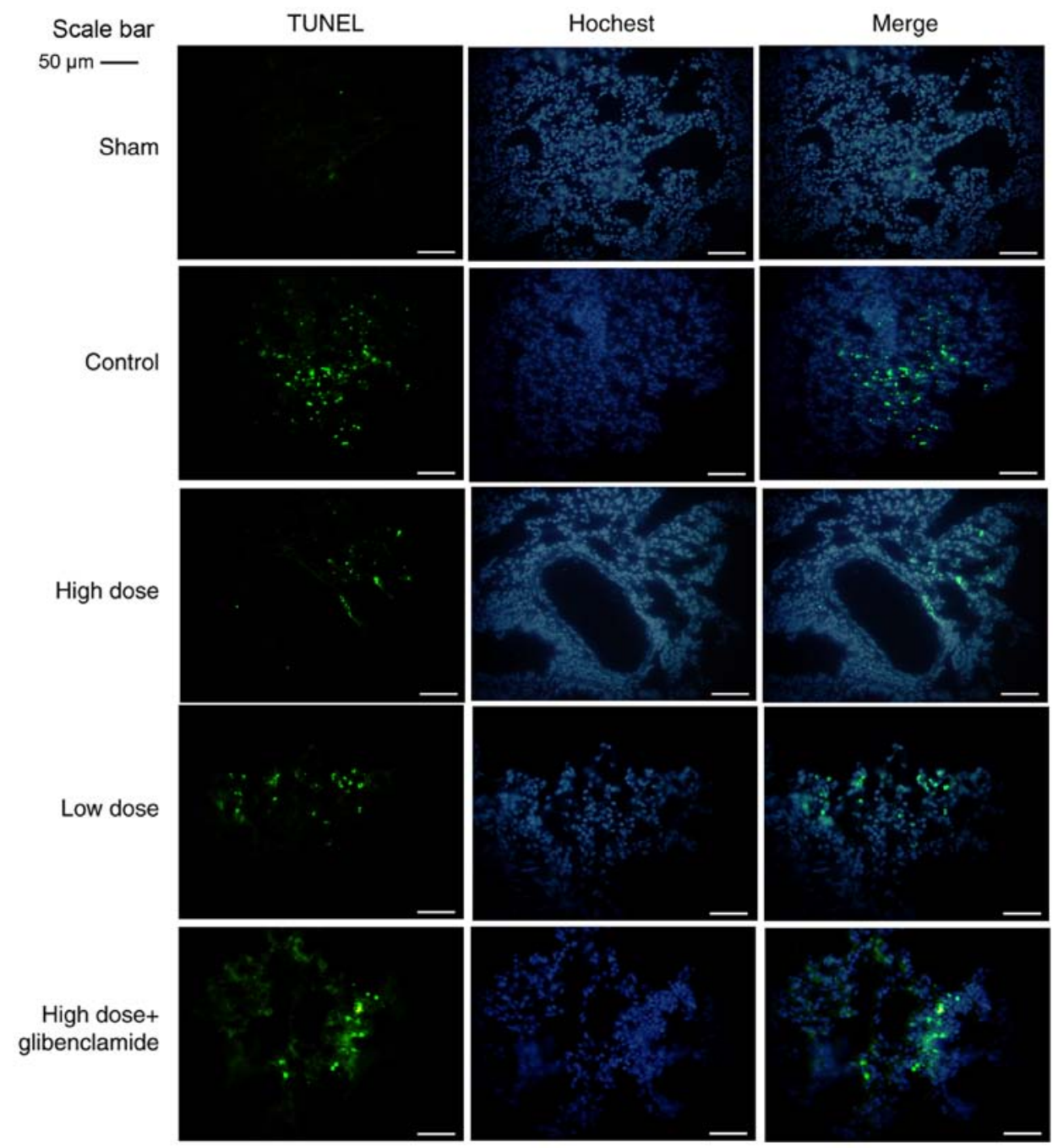

Figure 5. Effects of nicorandil on apoptosis in the lung. Apoptosis was analyzed using a TUNEL assay. Scale bar=50 $\mu \mathrm{m}$. TUNEL, TdT-mediated dUTP nick end labeling.
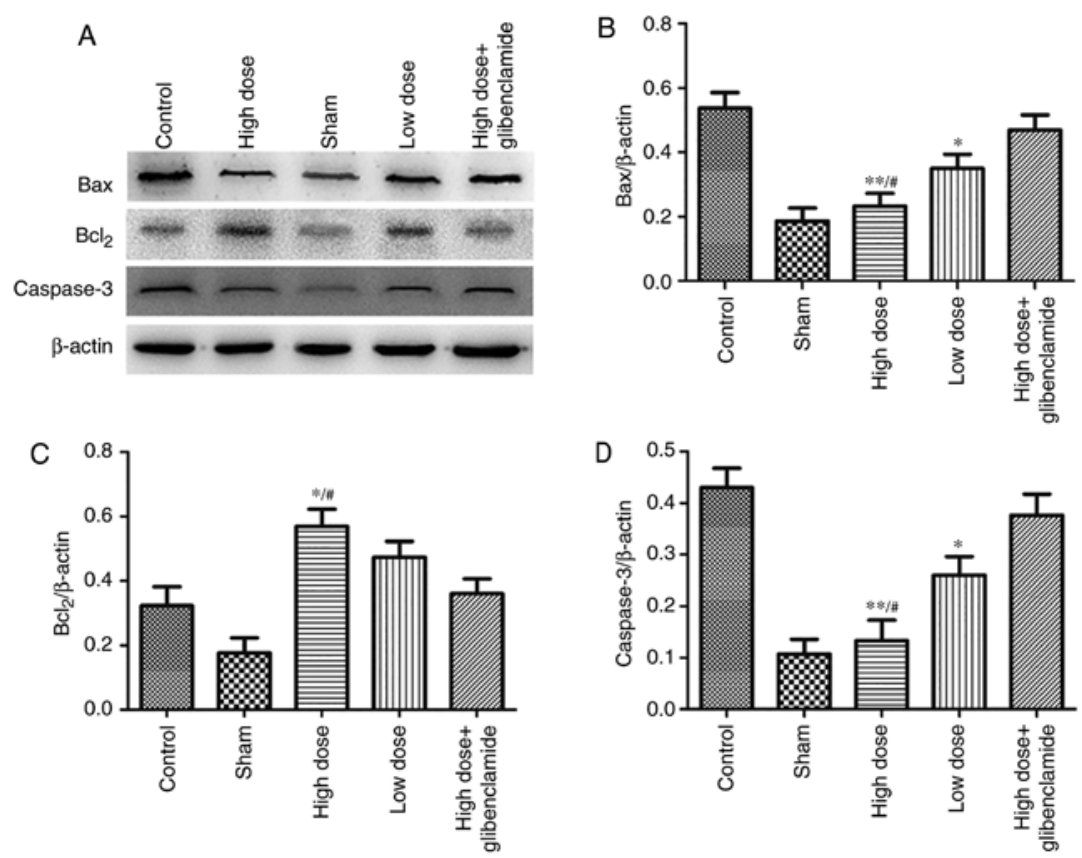

Figure 6. Effects of nicorandil on the expression of apoptosis-related molecules. (A) Effects were detected by western blot analysis. (B) Nicorandil downregulated the expression of Bax, (C) upregulated the expression of Bcl2 and (D) downregulated the expression of caspase-3 proteins in the collapsed lung. $\beta$-actin served as the internal standard for the western blot analysis. ${ }^{*} \mathrm{P}<0.05$ and ${ }^{* *} \mathrm{P}<0.01$ vs. control group; ${ }^{\prime} \mathrm{P}<0.05$ vs. glibenclamide group. 


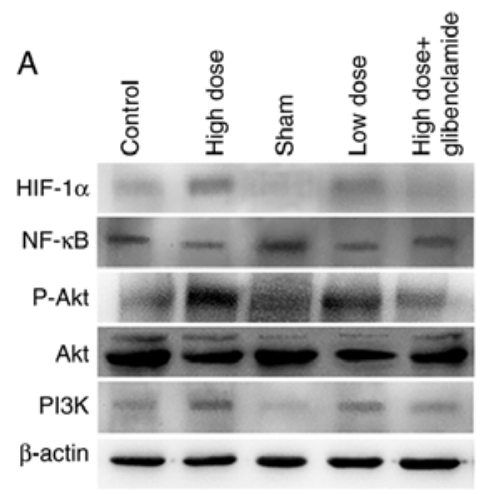

B
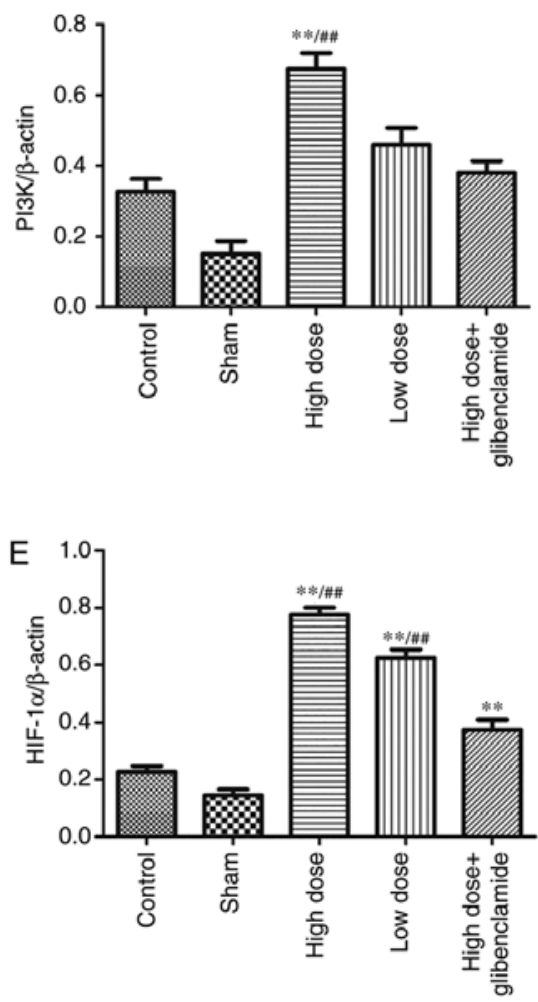

C

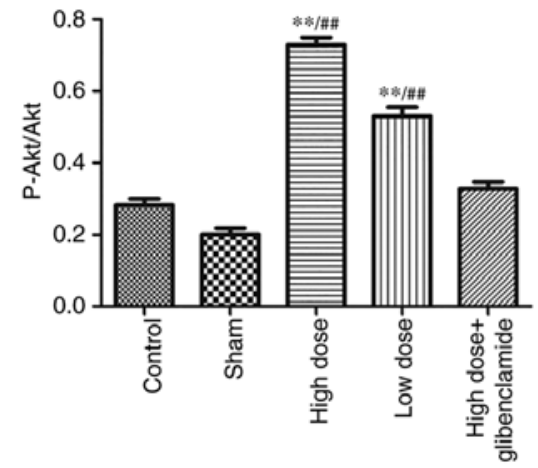

$\mathrm{F}$

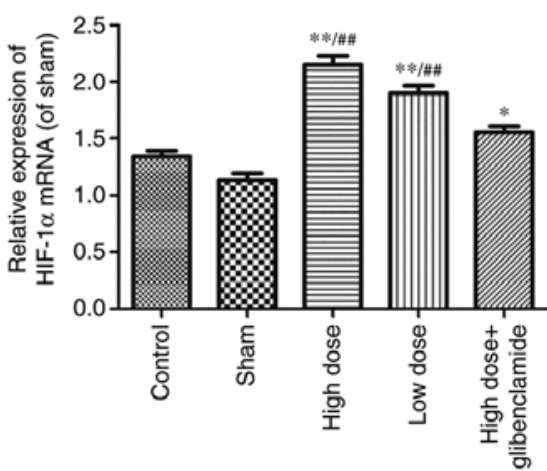

Figure 7. Effects of nicorandil on the signaling pathway was detected by western blotting and reverse transcription-quantitative polymerase chain reaction analysis. (A) Western blot analysis revealed that nicorandil upregulated the protein expression of (B) PI3K and (C) p-Akt in the collapsed lung, but (D) downregulated the protein expression of NF- $\mathrm{kB}$. Nicorandil also upregulated the (E) protein and (F) mRNA expression of HIF-1 $\alpha$. GAPDH served as the internal standard for mRNA analysis. $\beta$-actin served as the internal standard for the western blot analysis. ${ }^{~} \mathrm{P}<0.05$ and ${ }^{* *} \mathrm{P}<0.01$ vs. control group; ${ }^{\# \#} \mathrm{P}<0.01$ vs. glibenclamide group. PI3K, phosphatidylinositol-3-kinase; Akt, protein kinase B; p-, phosphorylated; NF-kB, nuclear factor-kB; HIF-1 $\alpha$, hypoxia inducible factor $1 \alpha$.
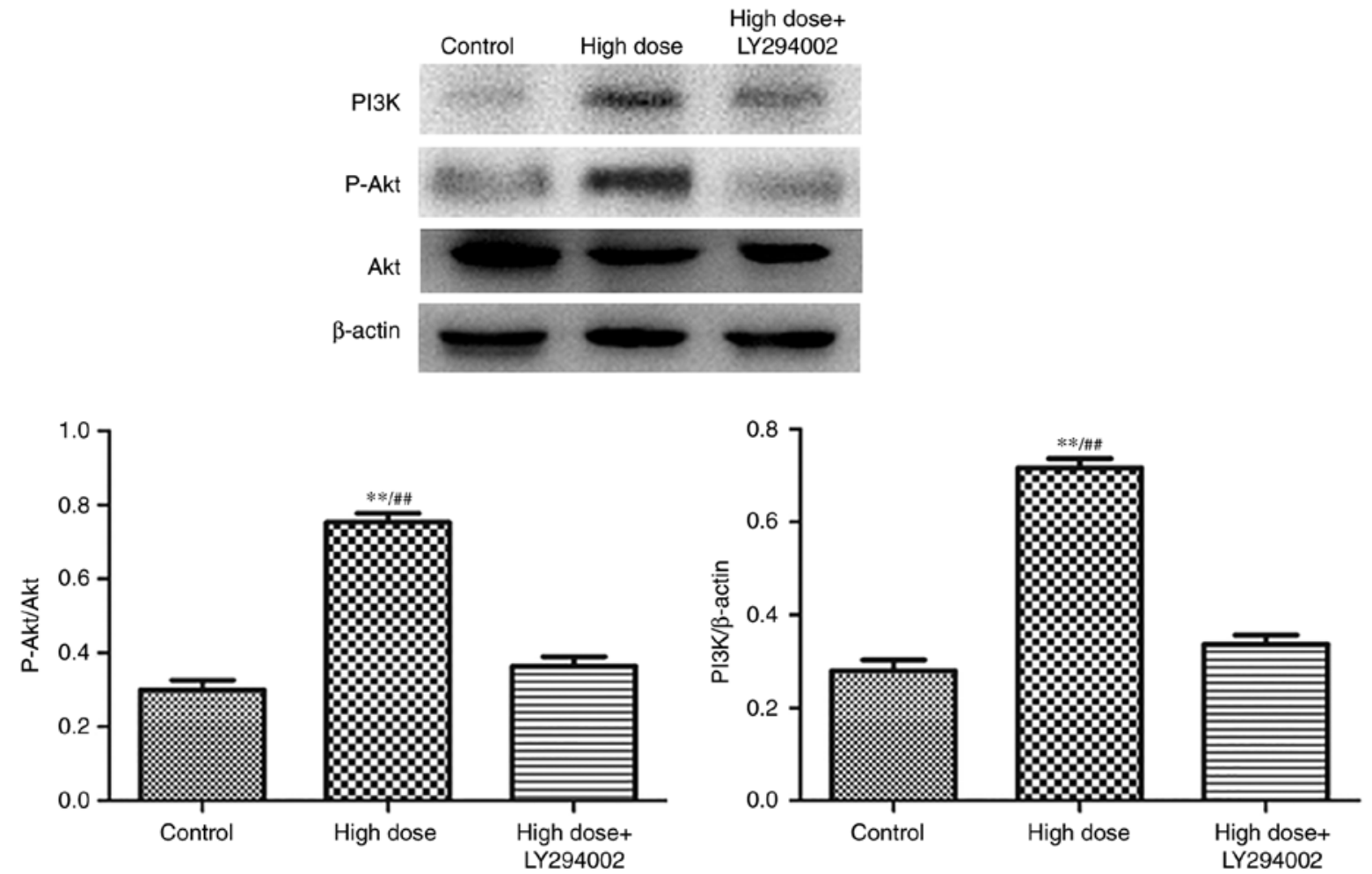

Figure 8. Effects of nicorandil on the PI3K/Akt signaling pathway are reversed by LY294002. Nicorandil upregulated the protein expression of PI3K and p-Akt in the collapsed lung. LY294002 downregulated the protein expression of PI3K and p-Akt in the collapsed lung. $\beta$-actin served as the internal standard for the western blot analysis. ${ }^{* *} \mathrm{P}<0.01$ vs. control group; ${ }^{\# \#} \mathrm{P}<0.01$ vs. LY294002 group. PI3K, phosphatidylinositol-3-kinase; Akt, protein kinase B; $\mathrm{p}-$, phosphorylated. 
technique (1). OLV must ensure the most convenient surgical field while maintaining adequate gas exchange and minimizing damage to the two lungs (38). Achieving this largely depends on how well the non-ventilatory lung is isolated from the other lung. It is well-known that ventilator-induced lung injury (VILI) (15) has a negative effect $(39,40)$ and a significant effect on patient prognosis $(41,42)$. Ventilation is increasingly recognized as a harmful intervention as it can cause lung injury, frequently referred to as VILI (43) and may injure the respiratory muscles, also termed ventilator-induced diaphragm dysfunction (VIDD) (44). The occurrence of hypoxemia in OLV mainly depends on correct placement of the double-lumen tube, the underlying disease, the setting of the ventilator and the experience of the anesthesiologist in thoracic surgery $(45,46)$. Accompanied by the imbalance of $\mathrm{V} / \mathrm{Q}, \mathrm{HPV}$ is significantly depressed during anesthesia. In addition to atelectasis, regions with low V/Q also contribute to typical arterial oxygenation defects during OLV (47), thus, shunting of the non-ventilatory lung is considered to be the leading cause of hypoxemia (48). Significant hypoxemia (22) occurs in 5-20\% of patients undergoing OLV due to increasing V/Q mismatching and intrapulmonary shunting $(49,50)$.

During OLV, nicorandil was found to significantly improve lung oxygenation, with notable changes in $\mathrm{SaO}_{2}$ and $\mathrm{PaO}_{2}$ under general anesthesia. The reversal of the index following the use of glibenclamide (specific antagonist) demonstrated that the protective effects of nicorandil on the lung relied on mitoKATP. The result of W/D ratio detection indicated that the infusion of nicorandil protected the respiratory membrane, preventing it from thickening. Therefore, the lung had little edema, which was the protective mechanism of nicorandil. The results showed that the microstructure of the non-ventilatory lung, which was improved following the implementation of a high dose of nicorandil, was seriously damaged in the control group, including the nuclei, membrane and alveolar wall. H\&E staining revealed that the high-dose group, similar to the sham group, exhibited less serious damage to the alveolar structure, with minimal hemorrhage, congestion and infiltration of inflammatory cells. The alveolar wall exhibited no congestion, thickening or exudation. These results were partially reversed by glibenclamide. The electron microscopy images also revealed that the high-dose group, similar to the sham group, led to no pyknosis or lobulation of nuclei, and no significant emptying of lamellar bodies or decreasing of microvilli in type II epithelial cells. These results were also partially reversed by glibenclamide. Taken together, these results demonstrated that nicorandil had a protective effect on the collapsed lung in terms of its microstructure and function. Therefore, the mechanism underlying its protective role became an important focus of the present study, which inferred it may affect oxidative stress in the lungs.

Nieman et al (51) also suggested that mechanical ventilation can result in lung damage, also caused by OLV, owing to $\mathrm{I} / \mathrm{R}$ lung injury from the collapse and re-expansion of the operated lung during OLV (52). A high pressure of oxygen in hypoxic-ischemic lung tissue may lead to reactive oxygen species production, cell damage and local leukocyte infiltration. The quantity of oxygen free radicals is proportional to the duration of OLV $(37,53)$. Re-expansion of the collapsed lung at the end of surgery and high airway pressure during mechanical ventilation may be other causes of lung injury besides I/R. It has been reported $(54,55)$ that re-expansion of the operated lung can lead to increased expression of inflammatory mediators $(56,57)$. The mechanism of $I / R$ injury, which is more complex, is currently considered to be associated with reactive oxygen species, endothelial cell injury, increased vascular permeability, and activation of neutrophils and the complement system, which also activates a series of inflammatory reactions and results in a large accumulation of inflammatory cytokines. In the present study, it was found that the concentrations of MDA and TNF- $\alpha$ in the control group were significantly higher than those in the high-dose group, which confirmed that the mechanism of nicorandil was to reduce oxidative stress and inflammatory reaction. SOD, which can eliminate reactive oxygen species generated by organisms, is important in decreasing I/R injury. Chen et al (58) found that SOD had protective effect and led to a significant change in the morphology of myocardial I/R injury, mainly due to the reduction of oxidative stress. The present study also found that nicorandil reduced I/R injury to protect lung function via SOD, which was high in the nicorandil group.

In addition, TUNEL staining, which revealed another mechanism, indicated that nicorandil significantly reduced apoptosis, the start of structural and functional damage. In the present study, nicorandil had a protective effect, regulated by apoptosis-related genes. Bcl 2 family members, which can be divided into two categories, are crucial in apoptosis. One category comprises anti-apoptotic members, including $\mathrm{Bcl} 2$ and Bcl-xl. The other promotes apoptotic rate, including Bax and Bak. Bax protein, which inhibits $\mathrm{Bcl} 2$, can form a heterodimer with $\mathrm{Bcl} 2$. Caspase-3 is a protease identified by Fernandez-Alnemri in 1994, which was named caspase-3 in 1996. Caspase-3 is now considered the most important terminal enzyme, which serves an irreplaceable role in the process of apoptosis. It has been found that the apoptosis (59) in lung injury can be regulated by the $\mathrm{Bax} / \mathrm{Bcl} 2$ ratio and the expression of downstream Bax and $\mathrm{Bcl} 2$ genes (60), and can be inhibited by downregulating the main executive protein, caspase-3 (24). The present study found that, compared with the control group, the gene expression of Bax in the high-dose group was significantly downregulated, whereas the $\mathrm{Bcl} 2$ gene was significantly upregulated. When the $\mathrm{Bax} / \mathrm{Bcl} 2$ ratio declined, the protein expression of caspase-3 decreased significantly. As a result, there was minimal apoptosis in the high-dose group. This effect was reversed by glibenclamide, however, the effect in the high-dose of nicorandil group was significantly higher than that of the low-dose group. These results demonstrate the important mechanisms comprising the reduced expression of caspase- 3 and downregulation of the $\mathrm{Bax} / \mathrm{Bcl} 2$ ratio, which resulted in reduced hypoxemia, oxidative stress and I/R injury, and improved microstructure in the operated lung in the high-dose group through decreased apoptosis.

As nicorandil can activate the opening of mitoKATP to protect cells, it has been confirmed $(14,61)$ that the cytoprotective effect of nicorandil relies on the PI3K/Akt signaling pathway, which is a classical pathway involved in cell proliferation, differentiation and apoptosis. The phosphorylation of Akt (p-Akt) can activate inhibitor of NF- $\mathrm{NB}(\mathrm{I} \kappa \mathrm{B})$ kinase, resulting in the degradation of $\mathrm{I} \kappa \mathrm{B}$, an inhibitor of $\mathrm{NF}-\kappa \mathrm{B}$, 
which is released from the cytoplasm for nuclear translocation and activates its target gene to promote cell survival. However, the increase of NF- $\kappa \mathrm{B}$ following I/R injury promotes the transcription of downstream genes of additional cytokines $(62,63)$, including TNF- $\alpha$ (64), interleukin-1 $\beta$, inducible nitric oxide synthase and cyclooxygenase 2 . In lung injury of mechanical ventilation, activated $\mathrm{NF}-\kappa \mathrm{B}$ can lead to the production of a large number of chemokines and cytokines and the recruitment of neutrophils, monocytes, macrophages and lymphocytes, which trigger pulmonary inflammatory responses (65).

In the present study, the expression levels of PI3K, $\mathrm{p}$-Akt and the p-Akt/Akt ratio in the high-dose group were upregulated, and reversed by glibenclamide and LY294002, indicating that nicorandil acted on mitoKATP through the PI3K/Akt pathway to inhibit apoptosis in the non-ventilatory lung. In addition, $\mathrm{NF}-\kappa \mathrm{B}$, which is closely associated with the inflammatory reaction, was downregulated in the high-dose group, whereas HIF-1 $\alpha$, a nuclear transcription factor, was upregulated, and these effects were reversed by its antagonist, glibenclamide. It was also demonstrated that a high dose of nicorandil had better results compared with a low dose. These results were consistent with the two previous independent studies $(66,67)$, which demonstrated that the expression of NF- $\kappa \mathrm{B}$ and mitochondrial apoptotic pathway were first inhibited in pulmonary vascular endothelial cells following the opening of mitochondrial potassium channels. The expression of HIF-1 $\alpha$ is regulated by oxygen concentration, specifically activated in hypoxia and initiated firstly in endogenous protective mechanisms (68). Zhao et al (69) showed that HIF-1 $\alpha$ is one of the important mechanisms of I/R lung injury following the application of DMOG, an HIF-1 $\alpha$ stabilizing agent. The results of the present study are partially consistent with those of Wan et al (70). Hypoxia and I/R in OLV can lead to the overloading of intracellular calcium, and the overload of calcium into mitochondria over its translocation limit causes mitochondrial calcium overload, triggering opening of the mitochondrial membrane permeability transition pore (mPTP). Opening of the mPTP (71) uncouples the mitochondrial respiratory chain, and leads to membrane potential collapse and the release of cytochrome $c$ and other apoptotic factors, which ultimately leads to cell death. Nicorandil may serve a protective role by inhibiting the overload of calcium in mitochondria, thus triggering activation of the PI3K/Akt pathway, shutting of the mPTP, downregulating $\mathrm{NF}-\kappa \mathrm{B}$, upregulating $\mathrm{HIF}-1 \alpha$, and then downregulating $\mathrm{Bax} / \mathrm{Bcl} 2$, inhibiting caspase-3 and reducing apoptosis (72). However, further investigation of the specific mechanisms and concentration-response association are required to validate these findings.

In conclusion, nicorandil had a protective effect via inhibiting apoptosis in the non-ventilated lung, which had been collapsed and re-expanded during OLV, in the rabbit. This occurred through acting on mitoKATP through the PI3K/Akt signaling pathway.

\section{Acknowledgements}

The authors wish to thank Dr Maorong Jiang of the Laboratory Animal Center of Nantong University for their assistance in the preparation of the manuscript.

\section{Funding}

The present study was supported by the Natural Science Foundation of Jiangsu Province, China (grant no. BK20151268).

\section{Availability of data and materials}

The datasets supporting the conclusions of this study are included within the article.

\section{Authors' contributions}

$\mathrm{CW}$ and FJ designed the study; CW, HK and JC performed the experiments; XX and DS analyzed the data; CW and FJ wrote the manuscript. All authors read and approved the final manuscript.

\section{Ethics approval and consent to participate}

The experiments were reviewed and approved by the Ethics Committee for Animal Experimentation of Nantong University (Nantong, China).

\section{Patient consent for publication}

Not applicable.

\section{Competing interests}

The authors declare that they have no competing interests.

\section{References}

1. ShivaS,SackMN,GreerJJ,DuranskiM,Ringwood LA,BurwellL, Wang X, MacArthur PH, Shoja A, Raghavachari N, et al: Nitrite augments tolerance to ischemia/reperfusion injury via the modulation of mitochondrial electron transfer. J Exp Med 204: 2089-2102, 2007.

2. Liu B, Tewari AK, Zhang L, Green-Church KB, Zweier JL, Chen YR and He G: Proteomic analysis of protein tyrosine nitration after ischemia reperfusion injury: Mitochondria as the major target. Biochim Biophys Acta 1794: 476-485, 2009.

3. Pak O, Sydykov A, Kosanovic D, Schermuly RT, Dietrich A, Schröder K, Brandes RP, Gudermann T, Sommer N and Weissmann N: Lung ischaemia-reperfusion injury: The role of reactive oxygen species. Adv Exp Med Biol 967: 195-225, 2017.

4. Bernasconi $F$ and Piccioni FL: One-lung ventilation for thoracic surgery: Current perspectives. Tumori 103: 495-503, 2017.

5. Dolch ME, Choukèr A, Hornuss C, Frey L, Irlbeck M, Praun S, Leidlmair C, Villinger J and Schelling G: Quantification of propionaldehyde in breath of patients after lung transplantation. Free Radic Biol Med 85: 157-164, 2015.

6. Ju NY, Gao H, Huang W, Niu FF, Lan WX, Li F and Gao W: Therapeutic effect of inhaled budesonide (pulmicort ${ }^{\circledR}$ turbuhaler) on the inflammatory response to one-lung ventilation. Anaesthesia 69: 14-23, 2014.

7. Tojo K, Goto T and Kurahashi K: Protective effects of continuous positive airway pressure on a nonventilated lung during one-lung ventilation: A prospective laboratory study in rats. Eur J Anaesthesiol 33: 776-783, 2016.

8. Jung DM, Ahn HJ, Jung SH, Yang M, Kim JA, Shin SM and Jeon S: Apneic oxygen insufflation decreases the incidence of hypoxemia during one-lung ventilation in open and thoracoscopic pulmonary lobectomy: A randomized controlled trial. J Thorac Cardiovasc Surg 154: 360-366, 2017.

9. Xia R, Xu J, Yin H, Wu H, Xia Z, Zhou D, Xia ZY, Zhang L, Li H and Xiao X: Intravenous infusion of dexmedetomidine combined isoflurane inhalation reduces oxidative stress and potentiates hypoxia pulmonary vasoconstriction during one-lung ventilation in patients. Mediators Inflamm 2015: 238041, 2015. 
10. Huang SQ, Zhang J, Zhang XX, Liu L, Yu Y, Kang XH, Wu XM and Zhu SM: Can dexmedetomidine improve arterial oxygenation and intrapulmonary shunt during one-lung ventilation in adults undergoing thoracic surgery? A meta-analysis of randomized, placebo-controlled trials. Chin Med J (Engl) 130: $1707-1714,2017$

11. Schloss B, Martin D, Beebe A, Klamar J and Tobias JD: Phenylephrine to treat hypoxemia during one-lung ventilation in a pediatric patient. Thorac Cardiovasc Surg Rep 2: 16-18, 2013.

12. Yang J, Zhang J, Cui W, Liu F, Xie R, Yang X, Gu G, Zheng H, Lu J, Yang X, et al: Cardioprotective effects of single oral dose of nicorandil before selective percutaneous coronary intervention. Anatol J Cardiol 15: 125-131, 2015.

13. Saha KK, Kumar A, Deval MM, Saha KK, Jacob RV, Jagdale L and Kaul SK: Nicorandil infusion during off-pump coronary artery bypass grafting reduces incidence of intra-aortic balloon pump insertion. Innovations (Phila) 11: 123-127, 2016.

14. Su Q, Li L, Zhao J, Sun Y and Yang H: Effects of nicorandil on PI3K/Akt signaling pathway and its anti-apoptotic mechanisms in coronary microembolization in rats. Oncotarget 8 99347-99358, 2017.

15. Ahmed LA, El-Maraghy SA and Rizk SM: Role of the KATP channel in the protective effect of nicorandil on cyclophosphamide-induced lung and testicular toxicity in rats. Sci Rep 5: 14043,2015

16. Asarian L and Geary N: Sex differences in the physiology of eating. Am J Physiol Regul Integr Comp Physiol 305: R1215-R1267, 2013

17. Xu ZP, Gu LB, Bian QM, Li PY, Wang LJ, Chen XX and Zhang JY: A novel method for right one-lung ventilation modeling in rabbits. Exp Ther Med 12: 1213-1219, 2016.

18. You Z, Feng D, Xu H, Cheng M, Li Z, Kan M and Yao S: Nuclear factor-kappa B mediates one-lung ventilation-induced acute lung injury in rabbits. J Invest Surg 25: 78-85, 2012

19. Ito H, Taniyama $Y$, Iwakura K, Nishikawa N, Masuyama T, Kuzuya T, Hori M, Higashino Y, Fujii K and Minamino T: Intravenous nicorandil can preserve microvascular integrity and myocardial viability in patients with reperfused anterior wall myocardial infarction. J Am Coll Cardiol 33: 654-660, 1999.

20. Olson ME, McCabe K and Walker RL: Guaifenesin alone or in combination with ketamine or sodium pentobarbital as an anesthetic in rabbits. Can J Vet Res 51: 383-386, 1987.

21. Pérez-Martínez A, Gonzálvez-Piñera J, Marco-Macián A Carpintero-Moreno F and Moya-Marchante M: Propofol in continuous perfusion as anesthetic in experimental surgery in the rabbit. Rev Esp Anestesiol Reanim 42: 253-256, 1995 (In Spanish)

22. Bellis DJ, Day S and Barnes PK: The chronotropic effect of acetylcholine in the presence of vecuronium and atracurium. A study in the isolated perfused rabbit heart. Anaesthesia 45: 118-119, 1990.

23. Shinozawa E and Kawamura M: Anti-thrombotic effect of a factor Xa inhibitor TAK-442 in a rabbit model of arteriovenous shunt thrombosis stimulated with tissue factor. BMC Res Notes 11: 776, 2018

24. Lin L, Zhang L, Yu L, Han L, Ji W, Shen H and Hu Z: Time-dependent changes of autophagy and apoptosis in lipopolysaccharide-induced rat acute lung injury. Iran J Basic Med Sci 19: 632-637, 2016

25. Livak KJ and Schmittgen TD: Analysis of relative gene expression data using real-time quantitative PCR and the 2(-Delta Delta $\mathrm{C}(\mathrm{T}))$ method. Methods 25: 402-408, 2001.

26. Kostic J, Djordjevic-Dikic A, Dobric M, Milasinovic D, Nedeljkovic M, Stojkovic S, Stepanovic J, Tesic M, Trifunovic Z, Zamaklar-Tifunovic D, et al: The effects of nicorandil on microvascular function in patients with ST segment elevation myocardial infarction undergoing primary PCI. Cardiovasc Ultrasound 13: 26, 2015.

27. Wang YP, Zhang Y, Sun YR, Sun ZG, Zuo ZK, Feng ZR, Chang FY, Xu YC, Chen BZ and Ye YY: Effect of nicorandil on ventricular arrhythmia in patients with acute ST-segment elevation myocardial infarction underwent emergent percutaneous coronary intervention treatment. Zhonghua Xin Xue Guan Bing Za Zhi 45: 701-705, 2017 (In Chinese).

28. Suleimani HF, Eshraghi A, Daloee MH, Hoseini S and Nakhaee N: Effect of nicorandil on QT dispersion in patients with stable angina pectoris undergoing elective angioplasty: A triple-blind, randomized, placebo-controlled study. Electron Physician 9: 4934-4941, 2017.
29. Tanaka K, Kato K, Takano T, Katagiri T, Asanoi H, Nejima J, Nakashima M, Kamijo T and Sakanashi M: Acute effects of intravenous nicorandil on hemodynamics in patients hospitalized with acute decompensated heart failure. J Cardiol 56: 291-299, 2010.

30. Minami Y, Nagashima M, Kajimoto K, Shiga T and Hagiwara N: Acute efficacy and safety of intravenous administration of nicorandil in patients with acute heart failure syndromes: Usefulness of noninvasive echocardiographic hemodynamic evaluation. J Cardiovasc Pharmacol 54: 335-340, 2009.

31. Kong J, Ren G, Jia N, Wang Y, Zhang H, Zhang W, Chen B and Cao Y: Effects of nicorandil in neuroprotective activation of PI3K/AKT pathways in a cellular model of Alzheimer's disease. Eur Neurol 70: 233-241, 2013.

32. Yamazaki H, Oshima K, Sato H, Kobayashi K, Suto Y, Hirai K, Odawara H, Matsumoto K and Takeyoshi I: The effect of nicorandil on ischemia-reperfusion injury in a porcine total hepatic vascular exclusion model. J Surg Res 167: 49-55, 2011.

33. Shimizu S, Saito M, Kinoshita Y, Ohmasa F, Dimitriadis F, Shomori K, Hayashi A and Satoh K: Nicorandil ameliorates ischaemia-reperfusion injury in the rat kidney. Br J Pharmacol 163: 272-282, 2011

34. Szegedi LL, Bardoczky GI, Engelman EE and d'Hollander AA: Airway pressure changes during one-lung ventilation. Anesth Analg 84: 1034-1037, 1997.

35. Kilpatrick B and Slinger P: Lung protective strategies in anaesthesia. Br J Anaesth 105 (Suppl 1): i108-i116, 2010.

36. Szegedi LL, D'Hollander AA, Vermassen FE, Deryck F and Wouters PF: Gravity is an important determinant of oxygenation during one-lung ventilation. Acta Anaesthesiol Scand 54: 744-750, 2010.

37. Misthos P, Katsaragakis S, Milingos N, Kakaris S, Sepsas E, Athanassiadi K Theodorou D and Skottis I: Postresectional pulmonary oxidative stress in lung cancer patients. The role of one-lung ventilation. Eur J Cardiothorac Surg 27: 379-382; discussion 382-383, 2005 .

38. Licker M, Fauconnet P, Villiger Y and Tschopp JM: Acute lung injury and outcomes after thoracic surgery. Curr Opin Anaesthesiol 22: 61-67, 2009

39. Jeon K, Yoon JW, Suh GY, Kim J, Kim K, Yang M, Kim H, Kwon OJ and Shim YM: Risk factors for post-pneumonectomy acute lung injury/acute respiratory distress syndrome in primary lung cancer patients. Anaesth Intensive Care 37: 14-19, 2009.

40. Tusman G, Böhm SH, Warner DO and Sprung J: Atelectasis and perioperative pulmonary complications in high-risk patients. Curr Opin Anaesthesiol 25: 1-10, 2012.

41. Gajic O, Dara SI, Mendez JL, Adesanya AO, Festic E, Caples SM, Rana R, St Sauver JL, Lymp JF, Afessa B and Hubmayr RD: Ventilator-associated lung injury in patients without acute lung injury at the onset of mechanical ventilation. Crit Care Med 32: $1817-1824,2004$

42. Serpa Neto A, Cardoso SO, Manetta JA, Pereira VG, Espósito DC, Pasqualucci Mde O, Damasceno MC and Schultz MJ: Association between use of lung-protective ventilation with lower tidal volumes and clinical outcomes among patients without acute respiratory distress syndrome: A meta-analysis. JAMA 308: 1651-1659, 2012

43. Slutsky AS and Ranieri VM: Ventilator-induced lung injury. N Engl J Med 370: 980, 2014.

44. Levine S, Nguyen T, Taylor N, Friscia ME, Budak MT, Rothenberg P, Zhu J, Sachdeva R, Sonnad S, Kaiser LR, et al: Rapid disuse atrophy of diaphragm fibers in mechanically ventilated humans. N Engl J Med 358: 1327-1335, 2008

45. Karzai W and Schwarzkopf K: Hypoxemia during one-lung ventilation: Prediction, prevention, and treatment. Anesthesiology 110: 1402-1411, 2009

46. Ishikawa $S$ and Lohser J: One-lung ventilation and arterial oxygenation. Curr Opin Anaesthesiol 24: 24-31, 2011.

47. Kozian A, Schilling T, Schütze H, Heres F, Hachenberg T and Hedenstierna G: Lung computed tomography density distribution in a porcine model of one-lung ventilation. Br J Anaesth 102: 551-560, 2009

48. Benumof JL: One-lung ventilation and hypoxic pulmonary vasoconstriction: Implications for anesthetic management. Anesth Analg 64: 821-833, 1985.

49. Rozé H,Lafargue M and Ouattara A: Case scenario: Management of intraoperative hypoxemia during one-lung ventilation. Anesthesiology 114: 167-174, 2011.

50. Lee SM, Kim WH, Ahn HJ, Kim JA, Yang MK, Lee CH, Lee JH, Kim YR and Choi JW: The effects of prolonged inspiratory time during one-lung ventilation: A randomised controlled trial. Anaesthesia 68: 908-916, 2013 
51. Nieman GF, Satalin J, Andrews P, Aiash H, Habashi NM and Gatto LA: Personalizing mechanical ventilation according to physiologic parameters to stabilize alveoli and minimize ventilator induced lung injury (VILI). Intensive Care Med Exp 5: 8, 2017.

52. de Perrot M, Liu M, Waddell TK and Keshavjee S: Ischemia-reperfusion-induced lung injury. Am J Respir Crit Care Med 167: 490-511, 2003.

53. Cheng YJ, Chan KC, Chien CT, Sun WZ and Lin CJ: Oxidative stress during 1-lung ventilation. J Thorac Cardiovasc Surg 132: 513-518, 2006.

54. Riva DR, Contador RS, Baez-Garcia CS, Xisto DG, Cagido VR, Martini SV, Morales MM, Rocco PR, Faffe DS and Zin WA: Recruitment maneuver: RAMP versus CPAP pressure profile in a model of acute lung injury. Respir Physiol Neurobiol 169: 62-68, 2009

55. Rzezinski AF, Oliveira GP, Santiago VR, Santos RS, Ornellas DS Morales MM, Capelozzi VL, Amato MB, Conde MB, Pelosi P and Rocco PR: Prolonged recruitment manoeuvre improves lung function with less ultrastructural damage in experimental mild acute lung injury. Respir Physiol Neurobiol 169: 271-281, 2009.

56. Silva PL, Moraes L, Santos RS, Samary C, Ornellas DS, Maron-Gutierrez T, Morales MM, Saddy F, Capelozzi VL, Pelosi $\mathrm{P}$, et al: Impact of pressure profile and duration of recruitment maneuvers on morphofunctional and biochemical variables in experimental lung injury. Crit Care Med 39: 1074-1081, 2011.

57. Arnal JM, Paquet J, Wysocki M, Demory D, Donati S, Granier I Corno G and Durand-Gasselin J: Optimal duration of a sustained inflation recruitment maneuver in ARDS patients. Intensive Care Med 37: 1588-1594, 2011.

58. Chen C, Lu W, Wu G, Lv L, Chen W, Huang L, Wu X, Xu N and $\mathrm{Wu}$ Y: Cardioprotective effects of combined therapy with diltiazem and superoxide dismutase on myocardial ischemia-reperfusion injury in rats. Life Sci 183: 50-59, 2017.

59. Liu G, Zhang J, Chen H, Wang C, Qiu Y, Liu Y, Wan J and Guo H: Effects and mechanisms of alveolar type II epithelial cell apoptosis in severe pancreatitis-induced acute lung injury. Exp Ther Med 7: 565-572, 2014.

60. Wu Z, Dai F, Ren W, Liu H, Li B and Chang J: Angiotensin II induces apoptosis of human pulmonary microvascular endothelial cells in acute aortic dissection complicated with lung injury patients through modulating the expression of monocyte chemoattractant protein-1. Am J Transl Res 8: 28-36, 2016.

61. Yu D, Fan C, Zhang W, Wen Z, Hu L, Yang L, Feng Y, Yin KJ and Mo X: Neuroprotective effect of nicorandil through inhibition of apoptosis by the PI3K/Akt1 pathway in a mouse model of deep hypothermic low flow. J Neurol Sci 357: 119-125, 2015.
62. Broucek JR, Francescatti AB, Swanson GR, Keshavarzian A, Brand MI and Saclarides TJ: Unusual thrombotic complications. Am Surg 78: 728-729, 2012

63. Xia Z, Peng W, Cheng S, Zhong B, Sheng C, Zhang C, Gong W, Cheng S, Li J and Wang Z: Naoling decoction restores cognitive function by inhibiting the neuroinflammatory network in a rat model of Alzheimer's disease. Oncotarget 8: 42648-42663, 2017.

64. Ambros JT, Herrero-Fresneda I, Borau OG and Boira JM: Ischemic preconditioning in solid organ transplantation: From experimental to clinics. Transpl Int 20: 219-229, 2007

65. Suzuki T, Yamashita K, Jomen W, Ueki S, Aoyagi T, Fukai M, Furukawa H, Umezawa K, Ozaki M and Todo S: The novel NF-kappaB inhibitor, dehydroxymethylepoxyquinomicin, prevents local and remote organ injury following intestinal ischemia/reperfusion in rats. J Surg Res 149: 69-75, 2008.

66. Wang H, Zuo X, Wang Q, Yu Y, Xie L, Wang H, Wu H and Xie W: Nicorandil inhibits hypoxia-induced apoptosis in human pulmonary artery endothelial cells through activation of mitoKATP and regulation of eNOS and the NF- $\mathrm{B}$ pathway. Int J Mol Med 32: 187-194, 2013.

67. Xu CQ, Liu BJ, Wu JF, Xu YC, Duan XH, Cao YX and Dong JC: Icariin attenuates LPS-induced acute inflammatory responses: Involvement of PI3K/Akt and NF-kappaB signaling pathway. Eur J Pharmacol 642: 146-153, 2010.

68. Sakamoto N, Ishibashi T, Sugimoto K, Sawamura T, Sakamoto T, Inoue N, Saitoh S, Kamioka M, Uekita H, Ohkawara H, et al: Role of LOX-1 in monocyte adhesion-triggered redox, Akt/eNOS and $\mathrm{Ca}^{2+}$ signaling pathways in endothelial cells. J Cell Physiol 220: 706-715, 2009

69. Zhao X, Jin Y, Li H, Wang Z, Zhang W and Feng C: Hypoxia-inducible factor 1 alpha contributes to pulmonary vascular dysfunction in lung ischemia-reperfusion injury. Int $\mathbf{J}$ Clin Exp Pathol 7: 3081-3088, 2014

70. Wan J, Wu W, Chen Y, Kang N and Zhang R: Insufficient radiofrequency ablation promotes the growth of non-small cell lung cancer cells through PI3K/Akt/HIF-1 $\alpha$ signals. Acta Biochim Biophys Sin (Shanghai) 48: 371-377, 2016.

71. Gomez L, Li B, Mewton N, Sanchez I, Piot C, Elbaz M and Ovize M: Inhibition of mitochondrial permeability transition pore opening: Translation to patients. Cardiovasc Res 83: 226-233, 2009.

72. Forgiarini LA Jr, Grun G, Kretzmann NA, de Muñoz GA, de Almeida A, Forgiarini LF and Andrade CF: When is injury potentially reversible in a lung ischemia-reperfusion model? J Surg Res 179: 168-174, 2013. 